\section{Appendix B. Within-group analysis}

\section{TABLE B-1. Maternal pretreatment with betamethasone}

\begin{tabular}{lcc}
\hline Test pairs & $\begin{array}{c}\mathbf{T}_{\mathbf{0}}-\mathbf{T}_{\mathbf{6 0}} \\
(\boldsymbol{P} \text { value })\end{array}$ & $\begin{array}{c}\mathbf{T}_{\mathbf{0}}-\mathbf{T}_{\mathbf{1 5 0}} \\
(\boldsymbol{P} \text { value })\end{array}$ \\
\hline $\mathrm{pH}$ & $\mathrm{ns}$ & $<.05$ \\
$\mathrm{PaCO}_{2}(\mathrm{~mm} \mathrm{Hg})$ & $<.05$ & $<.05$ \\
$\mathrm{HCO}_{3}-(\mathrm{mmol} / \mathrm{L})$ & $\mathrm{ns}$ & $<.05$ \\
$\mathrm{O}_{2}$ Sat $(\%)$ & $<.05$ & $<.05$ \\
$\mathrm{HR}($ beats $/ \mathrm{min})$ & $\mathrm{ns}$ & $\mathrm{ns}$ \\
SBP $(\mathrm{mm} \mathrm{Hg})$ & $<.05$ & $\mathrm{~ns}$ \\
Glucose $(\mathrm{mg} / \mathrm{dL})$ & $<.05$ & $\mathrm{~ns}$ \\
Lactate $(\mathrm{mmol} / \mathrm{L})$ & $<.05$ & $<.05$ \\
ET1 $(\mathrm{pg} / \mathrm{mL})$ & $\mathrm{ns}$ & $<.05$ \\
ET2 $(\mathrm{pg} / \mathrm{mL})$ & $<.05$ & $\mathrm{~ns}$ \\
ET3 $(\mathrm{pg} / \mathrm{mL})$ & $<.05$ & $\mathrm{~ns}$ \\
CRF $(\mathrm{pg} / \mathrm{mL})$ & $\mathrm{ns}$ & $\mathrm{ns}$ \\
\hline P & &
\end{tabular}

$P$ value (Wilcoxon signed-rank test): bold font when $T_{0}$ is less than $T_{60}$ or $T_{150}$, and italic font when $T_{0}$ is greater than $T_{60}$ or $T_{150}$. Sat, Arterial oxygen saturation; $H R$, heart rate; $S B P$, systolic arterial blood pressure; $E T$, endothelin; $T_{0}$, baseline; $T_{60}$, end of cardiac bypass; $T_{150}$, end of the experiment.

TABLE B-2. Fetal treatment with methylprednisolone

\begin{tabular}{|c|c|c|}
\hline Test pairs & $\begin{array}{c}T_{0}-T_{60} \\
(P \text { value })\end{array}$ & $\begin{array}{c}\mathrm{T}_{0}-\mathrm{T}_{150} \\
(P \text { value })\end{array}$ \\
\hline $\mathrm{pH}$ & $<.05$ & $<.05$ \\
\hline $\mathrm{PaCO}_{2}(\mathrm{~mm} \mathrm{Hg})$ & $<.05$ & $<.05$ \\
\hline $\mathrm{HCO}_{3}{ }^{-}(\mathrm{mmol} / \mathrm{L})$ & ns & $<.05$ \\
\hline $\mathrm{O}_{2}$ Sat $(\%)$ & $<.05$ & $<.05$ \\
\hline HR (beats/min) & ns & ns \\
\hline $\mathrm{SBP}(\mathrm{mm} \mathrm{Hg})$ & ns & ns \\
\hline Glucose (mg/dL) & $<.05$ & ns \\
\hline Lactate (mmol/L) & $<.05$ & $<.05$ \\
\hline ET1 (pg/mL) & ns & ns \\
\hline ET2 (pg/mL) & ns & ns \\
\hline ET3 (pg/mL) & ns & $<.05$ \\
\hline CRF (pg/mL) & ns & ns \\
\hline
\end{tabular}

$P$ value (Wilcoxon signed-rank test): bold font when $T_{0}$ is less than $T_{60}$ or $T_{150}$, and italic font when $T_{0}$ is greater than $T_{60}$ or $T_{150}$. Sat, Arterial oxygen saturation; $H R$, heart rate; $S B P$, systolic arterial blood pressure; $E T$, endothelin; $T_{0}$, baseline; $T_{60}$, end of cardiac bypass; $T_{150}$, end of the experiment.

\section{Discussion}

Dr Mohan Reddy (Stanford, Calif). I have a couple of questions for you. First, where did you obtain your samples? Was it from the umbilical artery or from the venous site? Second, have you measured umbilical artery blood flows during this study? There is no significant difference in your placental function parameters, at least the blood gases.

Dr Carotti. Samples were always obtained from the right carotid artery, which was cannulated during the instrumentation of the animal.

We did not measure umbilical artery blood flow, and we are aware that this point may be a limitation of our study. However, I
TABLE B-3. Fetal CVVHD

\begin{tabular}{lcc}
\hline Test pairs & $\begin{array}{c}\mathbf{T}_{\mathbf{0}}-\mathbf{T}_{\mathbf{6 0}} \\
(\boldsymbol{P} \text { value })\end{array}$ & $\begin{array}{c}\mathbf{T}_{\mathbf{0}}-\mathbf{T}_{\mathbf{1 5 0}} \\
(\boldsymbol{P} \text { value })\end{array}$ \\
\hline $\mathrm{pH}$ & $<.05$ & $<.05$ \\
$\mathrm{PaCO}_{2}(\mathrm{~mm} \mathrm{Hg})$ & $<.05$ & $<.05$ \\
$\mathrm{HCO}_{3}-(\mathrm{mmol} / \mathrm{L})$ & $<.05$ & $\mathrm{~ns}$ \\
$\mathrm{O}_{2}$ Sat $(\%)$ & $<.05$ & $<.05$ \\
$\mathrm{HR}(\mathrm{beats} / \mathrm{min})$ & $\mathrm{ns}$ & $\mathrm{ns}$ \\
$\mathrm{SBP}(\mathrm{mm} \mathrm{Hg})$ & $\mathrm{ns}$ & $\mathrm{ns}$ \\
$\mathrm{Glucose}(\mathrm{mg} / \mathrm{dL})$ & $<.05$ & $\mathrm{~ns}$ \\
Lactate $(\mathrm{mmol} / \mathrm{L})$ & $\mathrm{ns}$ & $<.05$ \\
ET1 $(\mathrm{pg} / \mathrm{mL})$ & $\mathrm{ns}$ & $\mathrm{ns}$ \\
ET2 $(\mathrm{pg} / \mathrm{mL})$ & $\mathrm{ns}$ & $\mathrm{ns}$ \\
ET3 $(\mathrm{pg} / \mathrm{mL})$ & $\mathrm{ns}$ & $\mathrm{ns}$ \\
CRF $(\mathrm{pg} / \mathrm{mL})$ & $\mathrm{ns}$ & $\mathrm{ns}$ \\
\hline$P$ value $\left(\mathrm{Wilcoxon}\right.$ signed-rank test): bold font when $\mathrm{T}_{0}$ is less than $\mathrm{T}_{60}$ or \\
$\mathrm{T}_{150}$, and italic font when $\mathrm{T}_{0}$ is greater than $\mathrm{T}_{60}$ or $\mathrm{T}_{150}$. Sat, Arterial oxygen \\
saturation; $H R$, heart rate; $S B P$, systolic arterial blood pressure; $E T$, endo- \\
thelin; $T_{0}$, baseline; $T_{60}$, end of cardiac bypass; $T_{150}$, end of the experiment.
\end{tabular}

TABLE B-4. Control animals

\begin{tabular}{lcc}
\hline Test pairs & $\begin{array}{c}\mathbf{T}_{\mathbf{0}}-\mathbf{T}_{\mathbf{6 0}} \\
(\boldsymbol{P} \text { value })\end{array}$ & $\begin{array}{c}\mathbf{T}_{\mathbf{0}}-\mathbf{T}_{\mathbf{1 5 0}} \\
(\boldsymbol{P} \text { value })\end{array}$ \\
\hline $\mathrm{pH}$ & $<.05$ & $<.05$ \\
$\mathrm{PaCO}_{2}(\mathrm{~mm} \mathrm{Hg})$ & $<.05$ & $<.05$ \\
$\mathrm{HCO}_{3}{ }^{-}(\mathrm{mmol} / \mathrm{L})$ & $\mathrm{ns}$ & $\mathrm{ns}$ \\
$\mathrm{O}_{2}$ Sat $(\%)$ & $<.05$ & $<.05$ \\
$\mathrm{HR}(\mathrm{beats} / \mathrm{min})$ & $\mathrm{ns}$ & $\mathrm{ns}$ \\
SBP $(\mathrm{mm} \mathrm{Hg})$ & $<.05$ & $\mathrm{~ns}$ \\
$\mathrm{Glucose}(\mathrm{mg} / \mathrm{dL})$ & $<.05$ & $<.05$ \\
Lactate $(\mathrm{mmol} / \mathrm{L})$ & $<.05$ & $<.05$ \\
ET1 $(\mathrm{pg} / \mathrm{mL})$ & $\mathrm{ns}$ & $\mathrm{ns}$ \\
ET2 $(\mathrm{pg} / \mathrm{mL})$ & $\mathrm{ns}$ & $\mathrm{ns}$ \\
ET3 $(\mathrm{pg} / \mathrm{mL})$ & $\mathrm{ns}$ & $\mathrm{ns}$ \\
CRF $(\mathrm{pg} / \mathrm{mL})$ & $\mathrm{ns}$ & $\mathrm{ns}$
\end{tabular}

$P$ value (Wilcoxon signed-rank test): bold font when $T_{0}$ is less than $T_{60}$ or $T_{150}$, and italic font when $T_{0}$ is greater than $T_{60}$ or $T_{150}$. Sat, Arterial oxygen saturation; $H R$, heart rate; $S B P$, systolic arterial blood pressure; $E T$, endothelin; $T_{0}$, baseline; $T_{60}$, end of cardiac bypass; $T_{150}$, end of the experiment.

think that the main limitation of the study was the long run of $\mathrm{CB}$ without using an oxygenator. In fact, a linear relationship between CB duration and increase of placental vascular resistance has been demonstrated and is possibly enhanced by the absence of an oxygenator, leading to progressive placental dysfunction. Such a choice could explain why we did not find significant differences of blood gases between groups. However, although aware of such limitation, we selected this policy of CB anyway, because of the known linear relationship existing between bypass duration and related inflammatory reaction. In fact, the main aim of our study was to test the effects of steroids and CVVHD on the inflammatory response to $\mathrm{CB}$. 
Dr Reddy. The thing that seemed to make most difference was using an in-line axial flow pump in our experience, rather than any of the agents. We did not test hemodiafiltration, but that is something we will probably consider

Dr Carotti. I agree that the choice of the circuit is a main issue. Actually, we had some problems with the circuit that included an in-line axial flow pump, mainly during hemodiafiltration, because in general we could not obtain a blood flow rate higher than 1 $\mathrm{L} / \mathrm{min}$ at the fastest pump speed, using a $16 \mathrm{~F}$ venous cannula and a 3.5-mm arterial cannula. During filter perfusion, the pump appeared to be performing somewhat less well, and this probably caused some fetoplacental hypoperfusion in some of CVVHD fetuses. This is probably the main reason why CVVHD fetuses, which were performing very well during extracorporeal circulation, deteriorated quickly after discontinuation of the procedure.

Dr Renato S. Assad (São Paulo, Brazil). Due to the limitations of the cannula size, if you add a more complex circuit like a hemofilter in the circuit, I think you are going to need more flow. And due to the very small size of the patients we are planning to treat, maybe we should use an endothelium block rather than a hemofilter as Dr Hanley's group in San Francisco has shown. They use an endothelium block with an improvement of placental function after fetal cardiac bypass. Maybe going for something simple, rather than adding a more complex circuit, would be better for future clinical applications. I just would like to make this insight.

Dr Carotti. I agree with you that some pharmacologic agents can block the activity of the endothelium. However, in our experiment, the endothelium was probably only the last effector of an inflammatory amplification loop.

In our study we used hemodiafiltration without net ultrafiltration, a sort of hemodialysis, which per se did not eliminate great amounts of endothelins. We probably had a greater effect by removing even small amounts of molecules responsible for the initiation of an inflammatory amplification loop.

Therefore, we think that CVVHD helped in removing many more substances than endothelin alone. This is probably why we did not find the rebound of endothelins in animals treated by CVVHD, which one could have expected had removal of endothelins been managed by hemodiafiltration only.

CVVHD probably blocked an inflammatory amplification loop. I do not think that antagonists or endothelin blockers would have obtained the same effect.

Dr Frank L. Hanley (Stanford, Calif). I want to reemphasize the concern about your perfusion rates overall. The $\mathrm{pHs}$ in all of your groups drop fairly dramatically no matter what you did. With the filtration system in the circuit that is pulling off some of your flows, do you have any idea what your effective fetal placental perfusion rate was? You may have had hypoperfusion right from the very beginning here, which brings up another whole set of factors.

Dr Carotti. This is a good point. During our preliminary experience with fetal $\mathrm{CB}$, we were impressed by the flow limitations of an in-line axial flow pump (Hemopump) included within a conventional circuit. For this reason, we conducted an in vitro study in which we tested the performance of the Hemopump within the same circuit used for fetal CB at different pump preloads and afterloads. We found that at a preload of $5 \mathrm{~mm} \mathrm{Hg}$ and an afterload of $45 \mathrm{~mm} \mathrm{Hg}$, which corresponded respectively to the average mean right atrial and mean systemic blood pressure in our experiments, the maximal flow rate obtained at the fastest pump speed was $1 \mathrm{~L} / \mathrm{min}$.

After completion of each in vivo experiment, fetal weight was measured and the estimated blood flow perfusion during bypass was related to the real weight of each animal. It appeared that we obtained a blood flow rate of at least $300 \mathrm{~mL} \cdot \mathrm{kg}^{-1} \cdot \mathrm{min}^{-1}$ in all fetuses but in two of the CVVHD group. In those animals, possibly because of higher compliance of the system, we had a loss of $20 \%$ to $30 \%$ of the maximal flow rate.

So you are right: we got into fetoplacental hypoperfusion during CVVHD in two animals, and this was due to circuit limitations. 